\title{
Failure Theories on Carbon/Kevlar Hybrid Fabric Based Composite Laminate: Notch and Anisotropy Effects
}

\author{
Roberto José de Medeiros ${ }^{a}$, Selma Hissae Shimura da Nóbrega ${ }^{a}$, Eve Maria Freire de Aquino ${ }^{a}$ (D) \\ ${ }^{a}$ Programa de Pós-Graduação em Engenharia Mecânica, Centro de Tecnologia, Universidade Federal \\ do Rio Grande do Norte - UFRN, Natal, RN, Brasil
}

Received: February 08, 2018; Revised: February 21, 2019; Accepted: March 28, 2019

\begin{abstract}
Composite materials have been increasingly used in both researches and industries, given their wide range of innovative applications and configurations. High-performance hybrid fabric-reinforced plastics stand out in this sector. In the present research, an epoxy-based vinyl ester resin laminate reinforced with bidirectional hybrid fabric consisting of carbon and Kevlar fibers is developed. In order to determine its mechanical properties and damage mechanism considering the anisotropy and the presence of geometric discontinuity (circular hole), this research focused on both experimental and analytical aspect. Concerning to geometric discontinuity, in the vicinity of the hole (known as a stress concentration area), characteristic distances $a_{o}$ and $d_{o}$ associated to ASC (Average Stress Criterion) and PSC (Point Stress Criterion) failure theories, respectively, were determined. All the study of the composite material mechanical behavior was conducted based on uniaxial tensile tests. Their results show higher losses in the mechanical properties of the hybrid laminate, with respect to the anisotropy and the presence of the central hole, mainly when the orientation of the Kevlar fibers coincides with the direction of the applied load.
\end{abstract}

Keywords: Hybrid fabric, anisotropy, notch, carbon fibers, kevlar fibers, ASC and PSC failure theories.

\section{Introduction}

Technological advances and commercial demands have prompted an increase in the development of new materials in recent decades. Among these, polymer composite materials, also known as fiber-reinforced plastics (FRP) ${ }^{1,2}$, have a special highlight. Included in this category of composite materials there are the plastics reinforced with hybrid fabrics of high mechanical performance, ie, reinforcing fabrics made of synthetic fiber ${ }^{3-6}$.

The present study aims the investigation of the use of high-performance hybrid fabrics in manufacturing composite laminates with specific mechanical properties in the presence of geometric discontinuities. It is important to highlight here, the innovative aspect of this study with emphasis on the use of the hybrid reinforcement fabrics and the detailed analysis of the developed mechanical fracture characteristics.

Thus, an epoxy-based vinyl ester thermosetting polymer resin, reinforced with 8 layers of a bidirectional hybrid fabric (consisting of Kevlar fibers in the warp direction and carbon fibers in the weft direction), was produced. This composite laminate is defined as CL (Carbon/Kevlar Fiber - Bidirectional Hybrid Fabric Reinforced Composite Laminate).

The mechanical behavior of this CL was studied with both experimental and analytical focus in order to determine its mechanical and residual properties, in addition to the damage mechanism characteristics, considering the anisotropy of the hybrid fabric and the presence of geometric discontinuity (circular hole). The presence of a hole triggers stress concentration, a highly complex phenomenon in composite materials that has significant practical importance since its presence in structural elements is, normally, the cause of failures $^{7-16}$.

In the analysis of stresses in laminate composites with geometric discontinuities, it is necessary to understand the failure mode, the adequate use of failure theories, and the effects on the global response of the composite laminate ${ }^{17}$. The experimental technique is also important when analyzing the effects caused by stress concentration in laminate composites containing geometric discontinuities.

The initial analytical study is based on the calculation of the residual properties, using the concepts established by ASTM standard D 5766-11 ${ }^{18}$; such as residual strength (RS) and residual modulus (RM), both obtained experimentally. Next, these residual properties, and the PSC (Point Stress Criterion) and ASC (Average Stress Criterion) failure theories contained in the literature ${ }^{19}$ were used in semi-empirical determination of the characteristic distances ( $d_{o}$ and $a_{o}$ ) of the stress concentration area surrounding the hole. The aforementioned study considered the anisotropy of the hybrid fabric used as reinforcement and was conducted under uniaxial tensile loading.

As a complementary study, the $\mathbf{C L}$ was physically characterized using bulk density and calcination tests to 
obtain the contents (percentages) of the microstructural parameters (matrix, fibers and voids).

As a final step of the experiment, a global comparative study between the influences of anisotropy and geometric discontinuity on $\mathbf{C L}$ behavior was carried out, considering these parameters separately and simultaneously, in order to better understand the results and its influence. During this stage, the damage mechanism process of the laminate was studied and mechanical fracture was analyzed using scanning electron microscopy (SEM).

\section{Materials and Methods}

\subsection{Experimental procedure}

The hybrid laminate composite consisted of an hybrid bidirectional fabric reinforcement with a $2 \times 2$ twill weave, and a combination of two different types of fibers, namely ASS-4 (PAN) carbon fibers in the warp and Kevlar fibers/49 in the weft direction. The gram per square meter (GSM) weight of the hybrid fabric was $220 \mathrm{~g} / \mathrm{m}^{2}$ (industrially manufactured) and is commercially known as CKS-220, composed of 55\% carbon fibers and $45 \%$ Kevlar fibers (Fig. 1). An epoxy-based vinyl ester thermosetting polymer resin (Derakane 411-350) was used as matrix. The laminate composite consisted of 8 layers of reinforcement fabric identically superimposed according to the directions of the component fibers.

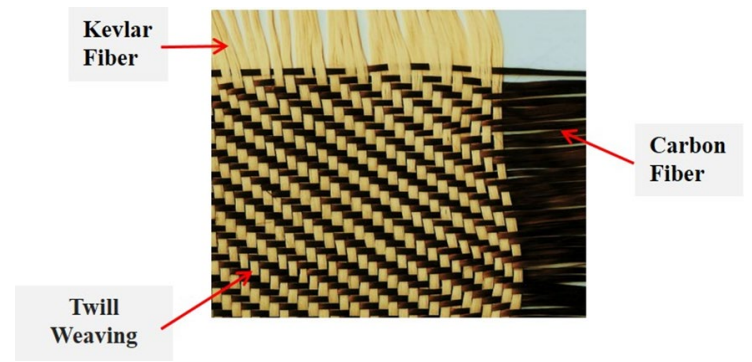

Figure 1. CKS-220 Carbon/Kevlar Hybrid Fabric.

The hybrid composite laminate was manufactured industrially as a plate $1100 \times 900 \times 3.2 \mathrm{~mm}$ (length, width and thickness, respectively) using the hand lay-up molding process.

The specimens identifications, associated with this hybrid composite laminate, are described below and used to better understand the comparative analyses between their mechanical properties:

- CLCO - CL specimens with carbon fibers in the direction of the applied load and in the original condition (without hole);

- CLKO - CL specimens with Kevlar fibers in the direction of the applied load and in the original condition (without hole);
- $\quad$ CLCH - CL specimens with carbon fibers in the direction of the applied load and with a circular hole;

- CLKH - CL specimens with Kevlar fibers in the direction of the applied load and with a circular hole.

The dimensions of the specimens without a hole were defined according to ASTM standard D 3039-14 ${ }^{20}$, while for those with a hole (centrally located); the ASTM standard D 5766-1 $11^{18}$ was applied. In the latter specimens (CLCH and $\mathrm{CLKH}$ ), the holes were made by continuous drilling to obtain a normalized hole diameter of $6.0 \mathrm{~mm}$ using drills equipped with diamond wire to prevent possible irregularities on the surface of the hole. Macroscopic and microscopic analyses revealed no delaminations or microcracks after drilling.

All specimens had a useful length (gage) of $127.0 \mathrm{~mm}$ and widths of $36.0 \mathrm{~mm}$ (CLCH and CLKH) and $25.0 \mathrm{~mm}$ (CLCO and CLKO). It is important to emphasize that all the specimen dimensions are within the standard tolerance $( \pm 1 \%)$.

The uniaxial tensile test was performed to determine the tensile strength and Young's modulus (in the direction of applied load) of the laminate under different conditions (anisotropy and hole). Eight specimens were manufactured for each condition (CLCH, CLKH, CLCO and CLKO), obtaining five valid tests according to the technical standard code. The tests were performed in a mechanical universal testing machine (Shimadzu AGI-250KN) with a maximum capacity of $250 \mathrm{KN}$.

The influence of tensile strength and elastic modulus losses in the laminate, due to the presence of the anisotropic properties and the central hole, was studied. The influence of the hole was determined by calculating the RS and RM (Residual Strength and Residual Modulus) of the laminated composite as well as the characteristic distances $\left(d_{o}\right.$ and $\left.a_{o}\right)$, according to PSC (Point Stress Criterion) and ASC (Average Stress Criterion) failure theories.

The density and content of the composites were established according to ASTM D792-1321 and ASTM D $3171-15^{22}$. The samples $(25.0 \times 25.0 \mathrm{~mm})$ were previously measured and weighed on a digital balance with maximum capacity of $210 \mathrm{~g}$ and resolution of $0.1 \mathrm{mg}$.

Due to fabric hybridization, some adjustments were made to test the temperature (ASTM standard D3171-15). The value of the first sample heating temperature $\left(450^{\circ} \mathrm{C}\right)$ was related to the loss of resin mass. The sample was weighed after 4 hours at this temperature; this weight corresponds to the volumetric fractions of the Kevlar and carbon fibers. This material, consisting only of fibers, was heated during 4 hours $h$ at a temperature that destroyed the Kevlar fibers $\left(550{ }^{\circ} \mathrm{C}\right)$, leaving only the carbon fibers. The residual mass of carbon fibers, after complete burning of the resin and the Kevlar fibers, was the initial parameter used to determine fiber, resin and void contents. The equations to determine these percentages can be found in ASTM standard D3171-15. 
These temperatures were determined from thermogravimetric analysis (TGA) ${ }^{23}$.

Macrostructural characterization of the mechanical fracture was conducted using HP PSC 1315 scanner images with a resolution of 1200ppi for all the uniaxial tensile tests. With respect to macroscopic analyses, scanning electron microscopy (SEM) was carried out using a Shimadzu SSX550 microscope, in order to determine the type of damage in the final section of the fracture.

\subsection{Analytical procedure - Failure theories: PSC and $A S C$}

The PSC criterion assumes that the failure occurs when the stress at a certain characteristic distance $d_{o}$ from the geometric discontinuity is greater than or equal to the ultimate strength of the laminate without the presence of geometric discontinuity. Thus, residual strength can be determined by equations 1 and $2^{19}$ :

$$
R S_{P S C}=\frac{\sigma_{N}}{\sigma_{U N}}=\frac{2}{2+\xi_{1}^{2}+3 \xi_{1}^{4}-(K-3)\left(5 \xi_{1}^{6}-7 \xi_{1}^{8}\right)}(1)
$$

where

$$
\xi_{1}=R /\left(R+d_{0}\right)
$$

and $R$ is defined as the radius of the hole, $K$ is the stress concentration factor, $\sigma_{N}$ and $\sigma_{U N}$ the failure stresses for situations with and without geometric discontinuities, respectively.

The ASC criterion assumes that failure occurs when the average stress at a certain characteristic distance $a_{o}$ is equal to the ultimate strength of the laminate without the presence of geometric discontinuity. As such, residual strength can be calculated by equations 3 and $4^{19}$ :

$$
R S_{A S C}=\frac{\sigma_{N}}{\sigma_{U N}}=\frac{2\left(1-\xi_{2}\right)}{2-\xi_{2}^{2}-\xi_{2}^{4}+(K-3)\left(\xi_{2}^{6}-\xi_{2}^{8}\right)}
$$

where

$$
\xi_{2}=R /\left(R+a_{0}\right)
$$

Once again, $R$ is defined as the radius of the hole, $K$ is the stress concentration factor, $\sigma_{N}$ and $\sigma_{U N}$ have the same definitions for the PSC theory, respectively.

\section{Results and Discussion}

\subsection{Volumetric density and constituent content}

The volumetric density, constituent content and the respective standard deviations of the composite laminate are shown in Table 1. Values recorded for bulk density and resin, fiber and void percentage are in accordance with other types of reinforcement (glass fiber coating) and the manufacturing process used ${ }^{24}$.
It is important to highlight that this characteristic of higher carbon fiber percentage in the CKS-220 hybrid fabric is also found in the hybrid composite laminate, with its value altered according to fiber density and composite laminate volume.

\subsection{Tensile test: $C L K O$ and CLCO specimens}

In order to achieve the objectives proposed in this study, that is, determine the influence of the anisotropy (intrinsic characteristic the hybrid fabric), discontinuity (characterized by a central hole), and the $\mathbf{C L}$ mechanical performance in uniaxial tensile loading, the stress $\mathrm{x}$ strain curves are shown.

The results of uniaxial tensile testing are presented in Figs. $2 \mathrm{a}$ and $2 \mathrm{~b}$ for the hybrid composite laminate $(\mathbf{C L})$ in the original condition (without hole), for both load directions. As observed, in general, the stress $\mathrm{x}$ strain curves exhibited linear behavior up to fracture.

This behavior is also characteristic of carbon fibers ${ }^{25}$ submitted to uniaxial tensile stress, as well as for some types of E-glass fiber-based composite laminates ${ }^{8}$. The same linear behavior between stress and strain was verified in another research ${ }^{26}$ only up to the load at damage onset (around 30\% of ultimate stress) for a similar hybrid composite laminate consisting of the same Kevlar/carbon hybrid fabric and impregnated with the same type of resin, but with 4 layers only. The constituent parameters of the laminate were $10.7 \%$ Kevlar fibers, $12.4 \%$ carbon fibers, $74.9 \%$ resin and $2 \%$ voids, that is, the percentages of fiber volume were much smaller than those of the $\mathbf{C L}$ depicted in Table 1.

The average values of tensile strength and Young's modulus (measured in the direction of the load) are shown in Table 2, along with the respective dispersions characterized by the absolute difference between the maximum and minimum values found in the tests. The Young's modulus corresponding to $50 \%$ of the rupture load was determined to avoid the influence of damage on the calculation.

In the same work mentioned above $\mathrm{e}^{26}$, considering the load applied in the direction of Kevlar fibers, the author found a lower stress $(365.87 \mathrm{MPa})$. In the current case, the composite laminate $(\mathbf{C L})$ showed a substantial increase in the load support capacity when the load was applied in the direction of the Kevlar fibers. However, the thinnest laminate continued to exhibit higher rigidity $(\mathrm{E}=9.33 \mathrm{GPa})$, the same behavior observed for CLCO specimens.

\subsection{Tensile test: $C L K H$ and $C L C H$ specimens}

Figures $3 \mathrm{a}$ and $3 \mathrm{~b}$ depict the mechanical behavior of the hybrid composite laminate $(\mathbf{C L})$ obtained from the results of uniaxial tensile testing, considering the presence of geometric discontinuity characterized by a central hole.

Similar to the original state, the stress $\mathrm{x}$ strain curves show linear behavior up to fracture for both load application directions. Table 3 shows the medium values of the tensile strength and Young's modulus (determined in the direction 
Table 1. Volumetric density and constituent content of the composite laminate.

\begin{tabular}{lccccc}
\hline $\begin{array}{l}\text { Composite } \\
\text { Laminate }\end{array}$ & $\begin{array}{c}\text { Volumetric Density } \\
\left(\mathrm{g} / \mathrm{cm}^{3}\right)\end{array}$ & $\begin{array}{c}\text { Volume fraction of } \\
\text { Kevlar fiber (\%) }\end{array}$ & $\begin{array}{c}\text { Volume fraction of } \\
\text { Carbon fiber (\%) }\end{array}$ & $\begin{array}{c}\text { Volume fraction of } \\
\text { matrix (\%) }\end{array}$ & $\begin{array}{c}\text { Volume fraction of } \\
\text { voids (\%) }\end{array}$ \\
\hline CL & $1.43 \pm 0.003$ & $25.5 \pm 0.018$ & $29.0 \pm 0.02$ & $44.8 \pm 0.034$ & $0.7 \pm 0.006$ \\
\hline
\end{tabular}

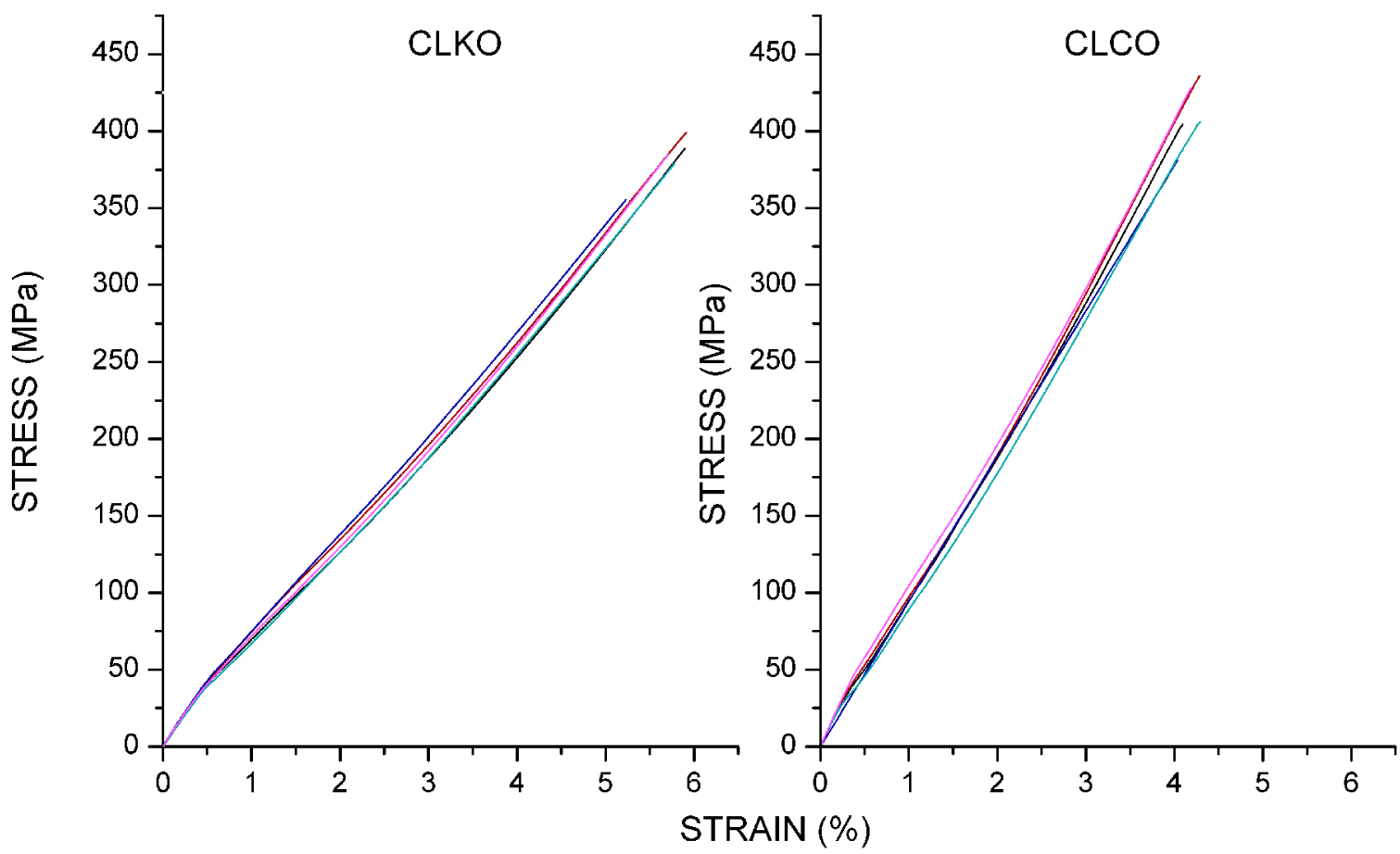

(a)

(b)

Figure 2. Stress x Strain curves. (a) CLKO specimens. (b) CLCO specimens.

Table 2. Tensile strength and Young's modulus. Original condition.

\begin{tabular}{lcccc}
\hline SP Specimens & Tensile strength $(\mathrm{MPa})$ & Dispersion $(\%)$ & Young's modulus (GPa) & Dispersion (\%) \\
\hline CLCO & 411.08 & 12.60 & 9.44 & 8.52 \\
CLKO & 381.35 & 10.95 & 6.44 & 7.27 \\
\hline
\end{tabular}

of the applied load) and, as in the previous study, for $50 \%$ of the rupture load in order to avoid any influence from damage. The values of their respective dispersions, calculated using the same procedure as earlier studies (original condition) are also shown.

The low dispersal values depicted in Tables 2 and 3 can be explained by the type of fabric hybridization. In others researches that exhibit significantly higher dispersion values, the same conditions of discontinuities and uniaxial tensile tests were applied, except the type of hybridization ${ }^{7}$.

\subsection{Comparison of the influence of the hole and anisotropy}

\section{Mechanical properties - Anisotropic influence}

Losses of tensile strength (7.23\%) and Young's modulus $(31.78 \%)$ caused by the presence of anisotropy in the hybrid fabric are shown in Figs. $4 \mathrm{a}$ and $4 \mathrm{~b}$.
Losses in mechanical response are evident in the CLKO test specimens when compared to CLCO test specimens, that is, when the load is applied in the direction of the Kevlar fibers, it shows worse mechanical composite laminate performance. This is perfectly explainable since, in terms of the elastic modulus, the AS4 carbon fiber is far superior (235 GPa) to that of Kevlar 49 fiber $(125 \mathrm{GPa})$. For tensile strength, the difference in properties is less pronounced, that is, for AS4 carbon fiber, its value 3.6 GPa and for Kevlar 49 fiber, it is $2.8 \mathrm{GPa}$, according to data supplied by the manufacturer of the hybrid fabric.

Mechanical properties - Influence of the central hole

The highest losses in mechanical properties due to the presence of a geometric discontinuity (central hole) were observed for the load applied in the direction of the Kevlar fibers. Figures 5a, 5b, 5c, and 5d show the influence of the 


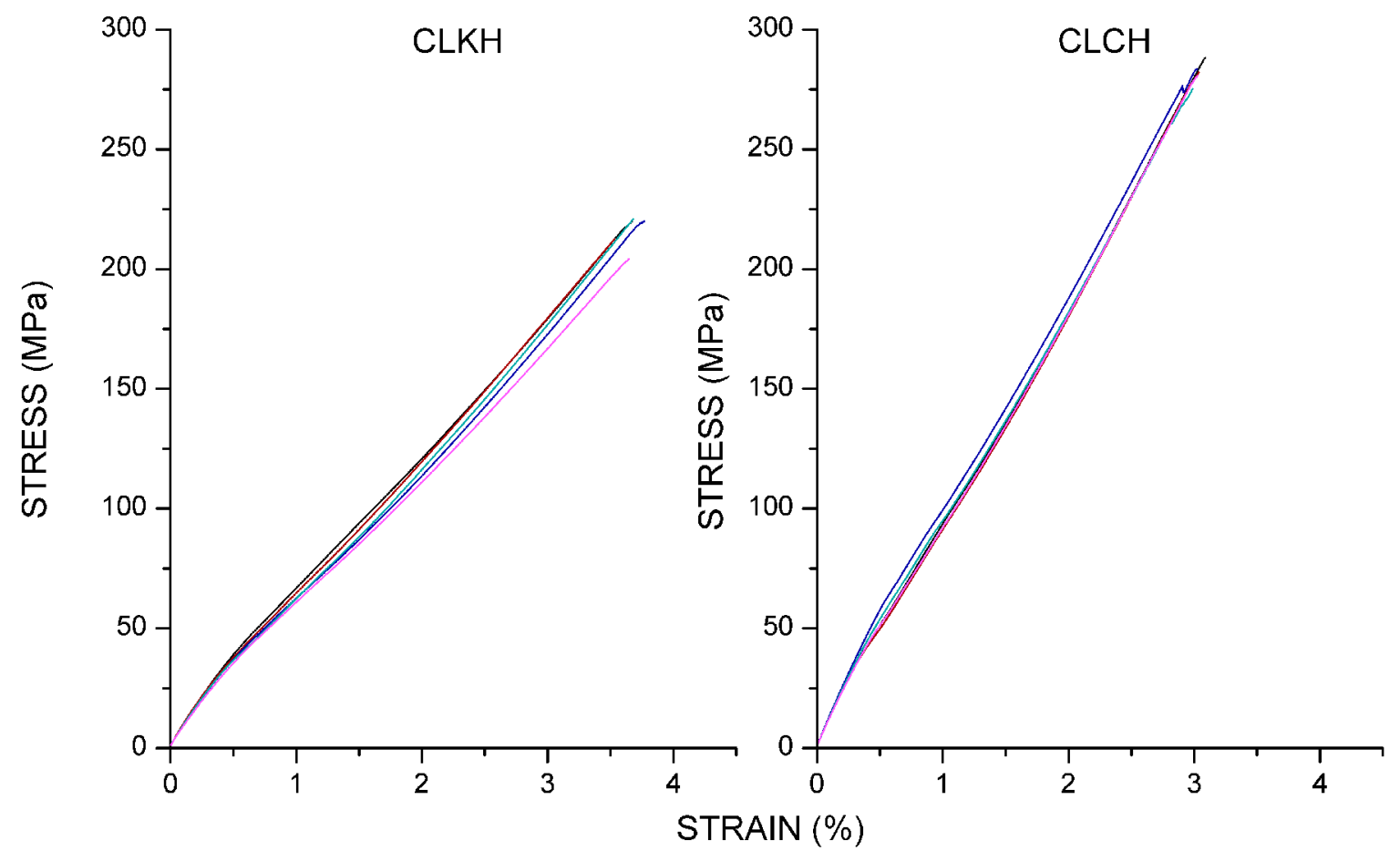

(a)

(b)

Figure 3. Stress x Strain curves. (a) CLKH specimens. (b) CLCH specimens.

Table 3. Tensile strength and Young's modulus. Central hole condition.

\begin{tabular}{lcccc}
\hline SP Specimens & Tensile strength $(\mathrm{MPa})$ & Dispersion $(\%)$ & Young's modulus (GPa) & Dispersion (\%) \\
\hline CLCH & 282.00 & 4.53 & 9.09 & 5.73 \\
CLKH & 215.55 & 7.50 & 5.84 & 8.65 \\
\hline
\end{tabular}

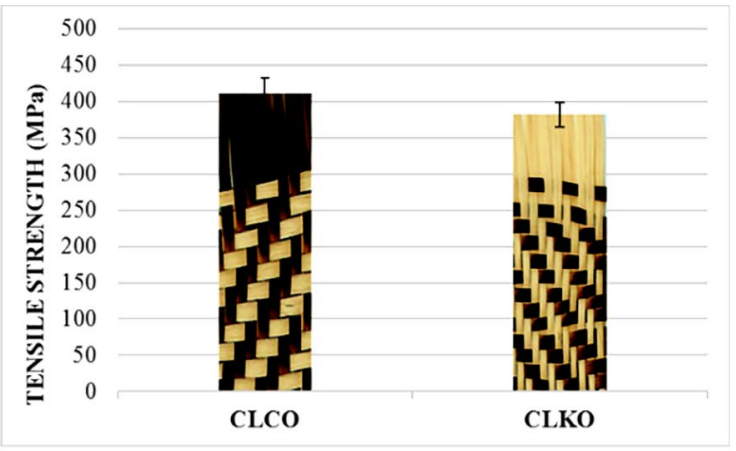

(a)

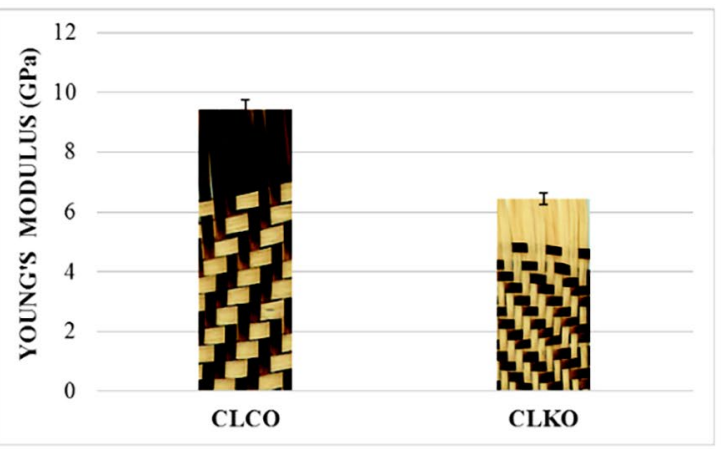

(b)

Figure 4. Comparative graph of the composite laminate $(\mathbf{C L})$ as a function of anisotropy. (a) Tensile strength. (b) Young's modulus.

central hole on tensile strength and Young's modulus for all the conditions studied. The losses are shown in Table 4.

Minimal losses were observed in the moduli compared to tensile strength. This is important in the study of residual properties because stress concentration can be considered dependent only on the geometry of the specimens. Similar to other studies, these results demonstrate that the presence of a central hole in composite laminates changes the rigidity behavior of these materials ${ }^{11,13}$.

Some studies involving hybridization and the presence of geometric discontinuity in composite laminates, such as $^{7,8}$, for a hybrid composite laminate consisting of different layers of E-glass/jute glass fiber bidirectional fabrics (different hybridization process from the CL studied here), 


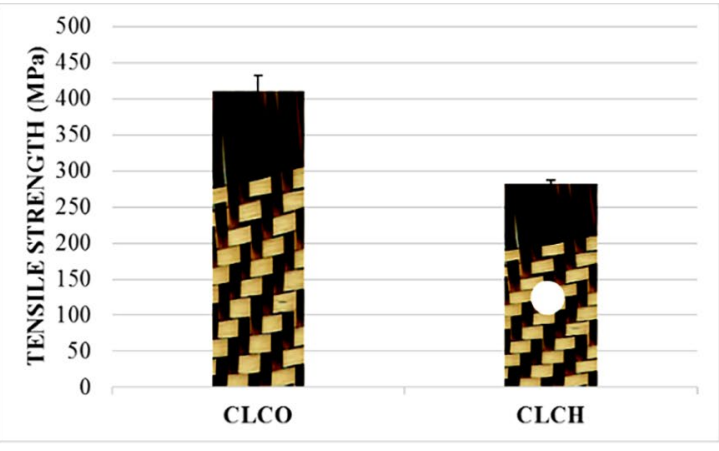

(a)

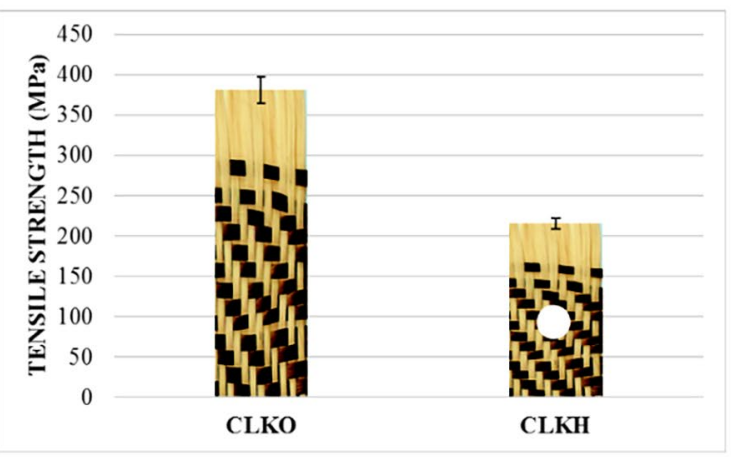

(c)

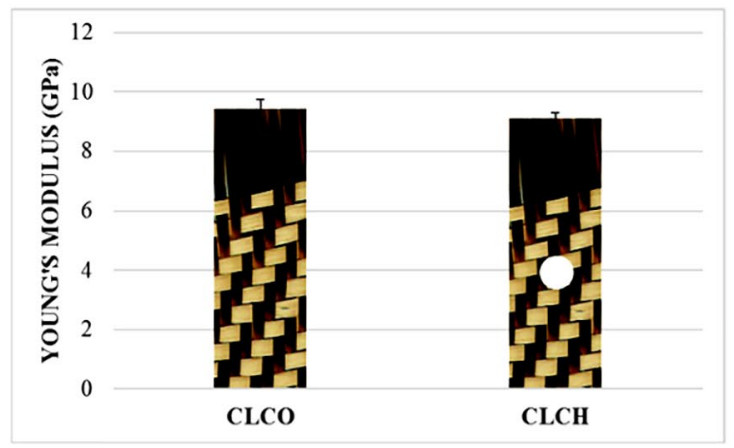

(b)

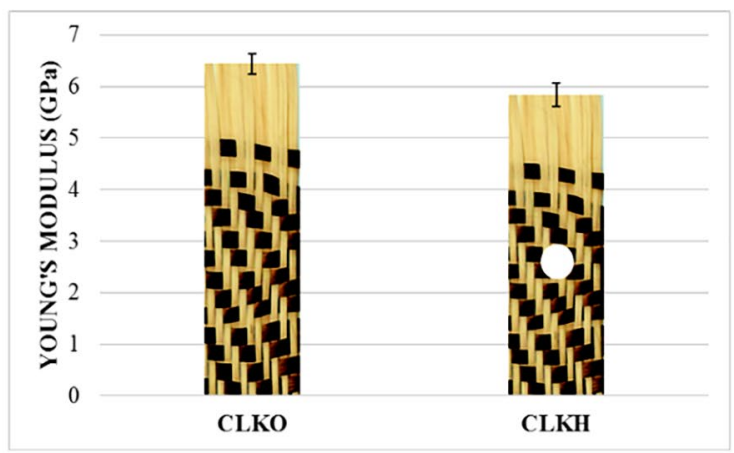

(d)

Figure 5. Comparative graph of the composite laminate $(\mathbf{C L})$ as a function of the presence of a central hole. (a) and (c) Tensile strength. (b) and (d) Young's modulus.

Table 4. Percentage losses in mechanical properties due to the presence of a hole.

\begin{tabular}{lcc}
\hline Specimens & Tensile Strength & Young's Modulus \\
\hline CLCH $<$ CLCO & $31.40 \%$ & $3.71 \%$ \\
CLKH $<$ CLKO & $43.48 \%$ & $9.31 \%$ \\
\hline
\end{tabular}

shows that, in the case of the standard central hole, losses in tensile strength and Young's modulus of $19 \%$ and $7.6 \%$, respectively, were found.

\section{Mechanical properties - Anisotropy with simultaneous influence of the hole}

The results of the anisotropy influence (orientation of the type of fiber in relation to the direction of the applied load) are presented and, in this case, the test specimens contain a central hole. This comparative study also aims at determining the ideal situation (least damaging) and which types of fibers should be considered in the direction of the applied load in the presence of stress concentration. In this respect, Figs. $6 \mathrm{a}$ and $6 \mathrm{~b}$ show the changes in the mechanical properties of the $\mathbf{C L}$.
Losses in mechanical response are greater for the CLKH test specimens than for the $\mathrm{CLCH}$ test specimens, that is, when the load is applied in the direction of the Kevlar fibers a worse mechanical composite laminate performance is observed for both tensile strength $(23.56 \%)$ and Young's modulus $(35.75 \%)$.

\subsection{Experimental residual properties: $R S$ and $R M$}

The comparative studies involving the residual properties of strength (RS) and elastic modulus (RM) for test specimens with a central hole are based on the $\mathbf{C L}$ in the original condition. The RS and RM for test specimens CLCH/CLCO and CLKH/CLKO were calculated according to ASTM standard D 5766-11 ${ }^{18}$. The values are shown in Table 5.

The experimental results show that the influence of geometric discontinuity is more damaging and intense considering mechanical strength than the elastic modulus of composite laminates reinforced with hybrid fabric, regardless of the type of fiber in which direction the load is applied.

The comparative study involving the simultaneous influence of anisotropy and the presence of a central hole 
between test specimens CLCH and CLKH can also be assessed based on strength and residual modulus, that is, the ability of the $\mathbf{C L}$ to maintain or preserve its load support limits and elastic properties.

- Residual Strength CLCH x Residual Strength CLKH: $+21.05 \%$;

- Residual Modulus CLCH x Residual Modulus CLKH: + 5.49\%;

For both strength and elastic modulus, the carbon fibers oriented in the direction of the applied load maintain their superior properties in the presence of stress concentration.

\subsection{Stress concentration - Failure theories: PSC and $A S C$}

\section{Semiempirical results: Specimens $\mathrm{CLCH}$ and $\mathrm{CLKH}$}

Studies show that a number of failure theories have been developed to predict the residual strength of hybrid material in the presence of a central hole, highlighting the Point Stress Criterion (PSC) and the Average Stress Criterion (ASC) failure theories ${ }^{19}$. Emphasized here that the RS values determined experimentally for the cases of test specimens with the presence of holes (CLCH and CLKH) and tested in the direction of carbon and Kevlar fibers are shown in Table 5.

Analysis of mechanical behavior exhibited by these test specimens and related to the elastic modulus (Tables 2 and 3 ) showed that the presence of a central hole does not change this laminate property (variation within the margin of dispersion). In this respect, the stress concentration factor to be used for the semiempirical calculation of distances $d_{o}$ and $a_{o}$ can be considered dependent only for the geometric parameters $R$ (radius) and $W$ (width) of the test specimens. The $\mathrm{K}$ value is $2.58^{27}$. Thus, knowing the values of $K, R$ ( 3 $\mathrm{mm})$ and experimental RS, and inputting them into equations

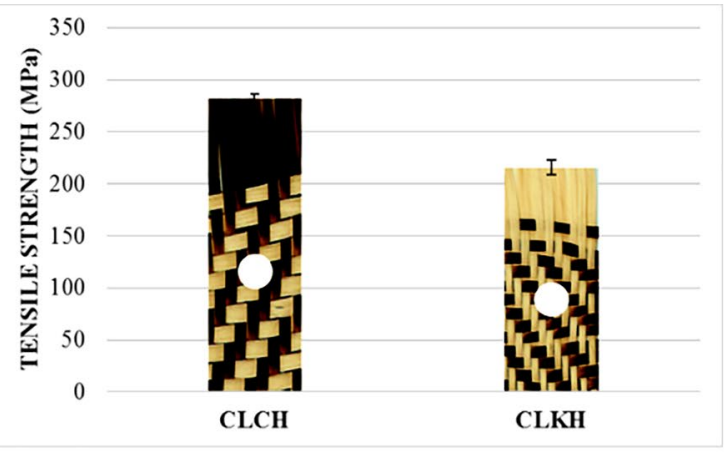

(a)
1 to 4 , the characteristic distances values, $d_{o}$ and $a_{o}$, for both failure theories (PSC and ASC) can be determined and shown in Table 6.

To better understand the results, Table 6 also depicts the values of the parameters calculated from other studies, considering the influence of anisotropy and hybridization for different types of composite laminates.

Analysis of the results showed a high percentage of loss in load support of the $\mathbf{C} \mathbf{L}$ in the presence of a central hole. This behavior indicates high stress concentration (shorter characteristic distances) when compared to other results obtained for different types of composite laminates, whether hybrid or reinforced with fabrics containing a single type of fiber ${ }^{4,13}$.

Table 5. Residual properties: strength and elastic modulus.

\begin{tabular}{lcc}
\hline Specimens & $\begin{array}{c}\text { Residual Strength } \\
\text { (RS) }\end{array}$ & $\begin{array}{c}\text { Residual Modulus } \\
\text { (RM) }\end{array}$ \\
\hline CLCH/CLCO & 0.68 & 0.96 \\
CLKH/CLKO & 0.56 & 0.91 \\
\hline
\end{tabular}

Table 6. Characteristic distances $d_{o}$ and $a_{o}$ for test specimens $\mathrm{CLCH}$ and CLKH.

\begin{tabular}{lccc}
\hline & & PSC $\boldsymbol{d}_{o}(\mathrm{~mm})$ & $\mathrm{ASC} \boldsymbol{a}_{o}(\mathrm{~mm})$ \\
\hline $\mathbf{C L C H}$ & 2.58 & 1.75 & 4.50 \\
$\mathbf{C L K H}$ & 2.58 & 1.02 & 2.35 \\
$C A_{\varnothing 6}^{A 4}$ & 2.58 & 0.81 & 1.80 \\
$C A_{\varnothing 6}^{C 4}$ & 2.58 & 1.48 & 4.00 \\
$\mathbf{M C}^{13}$ & 2.58 & 1.85 & 5.75 \\
$\mathbf{M C}^{13}$ & 3.0 & 1.75 & 5.75 \\
\hline
\end{tabular}

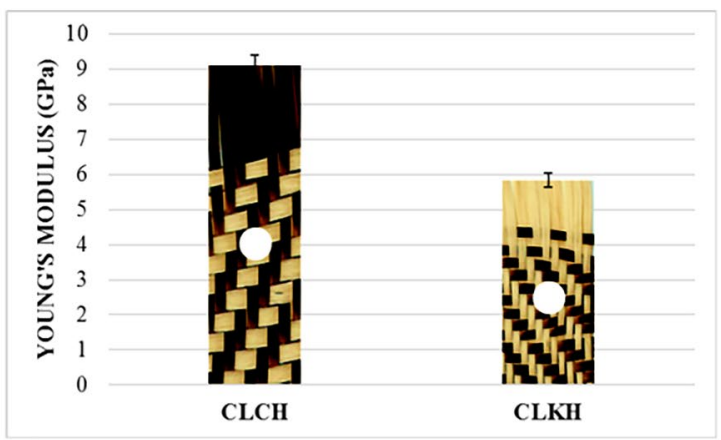

(b)

Figure 6. Comparative graph of the composite laminate $(\mathbf{C L})$ as a function of the simultaneous influence of anisotropy and a central hole. (a) Tensile strength. (b) Young's modulus. 


\subsection{Mechanical fracture - CLCO, CLKO, CLCH and CLKH specimens}

Macroscopic analysis of the fracture demonstrates that, regardless of the direction of the applied load (parallel to the direction of the carbon or Kevlar fibers) with or without the presence of a hole, test specimens CLCO, CLKO, CLCH and CLKH showed a localized fracture perpendicular to the direction of the applied load, see Figs. 7a, 7b, 7c and 7d.

All the test specimens showed a final LGM (lateralgage-middle) brittle fracture, according to the classification adopted by ASTM standard D 3039-14 ${ }^{20}$. In some test specimens cracking was observed in the matrix and close to the final fracture region.

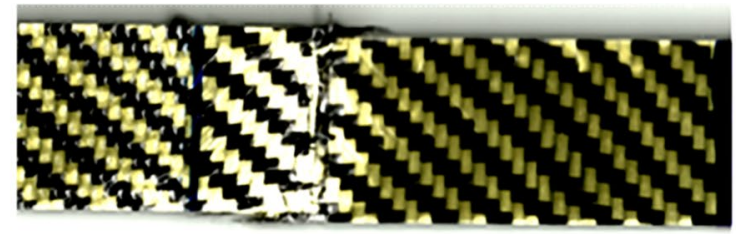

(a)

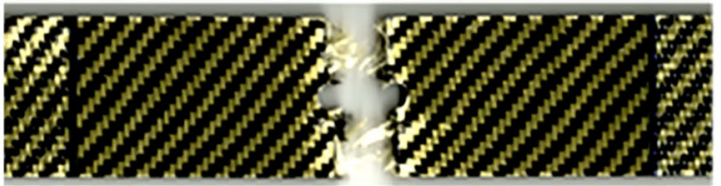

(c)
The different fracture characteristics (brittle and fraying) observed between carbon and Kevlar fibers, see Figs. 8a and $8 \mathrm{~b}$, had a direct influence on the formation and propagation of damage during loading.

Related to the microscopic analysis of the fracture, test specimens CLCO, CLKO, CLCH and CLKH exhibited common damage characteristics such as fiber fracture, adhesive fracture (fiber/matrix debonding), Kevlar fiber fraying, in addition to the cohesive fracture in the matrix, but with intensities and type of propagation depending on anisotropy and the presence of a circular hole. Figures 9a, $9 b, 9 c$, and $9 d$ show the influences on mechanical fracture obtained in the tests. Specimens CLKO and CLKH show more intense cracking in the matrix than that verified in CLCO and CLCH.

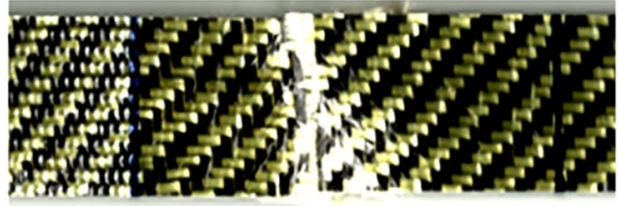

(b)
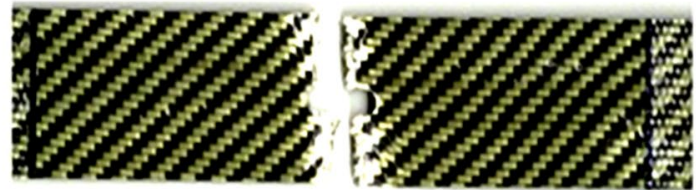

(d)

Figure 7. Mechanical fracture characteristics of the specimens: (a) CLCO; (b) CLKO; (c) CLCH; (d) CLKH.

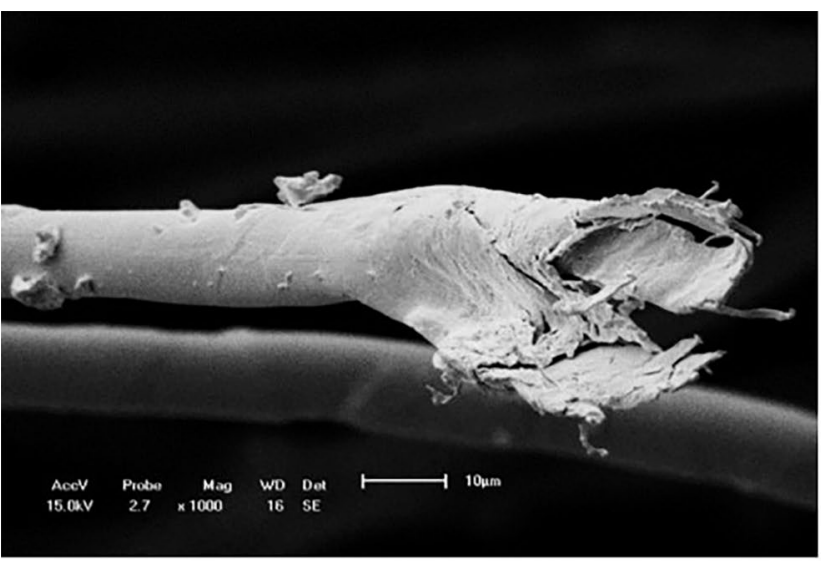

(a)

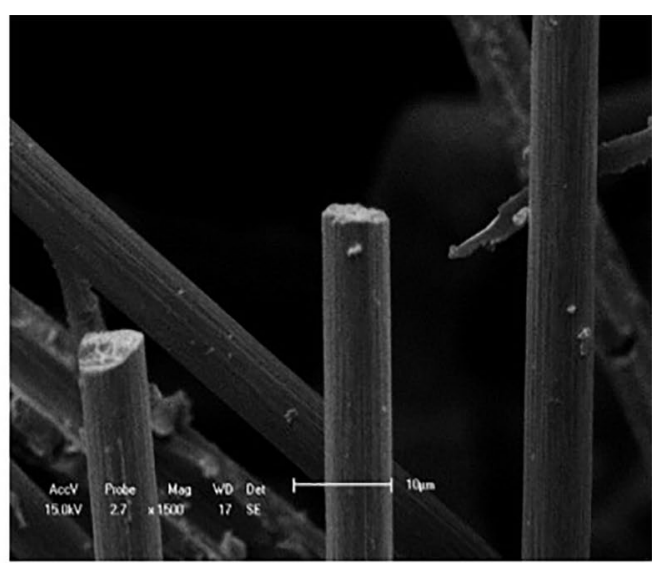

(b)

Figure 8. Different forms of mechanical fracture: (a) Kevlar fiber fraying; (b) carbon fiber brittle fracture. 


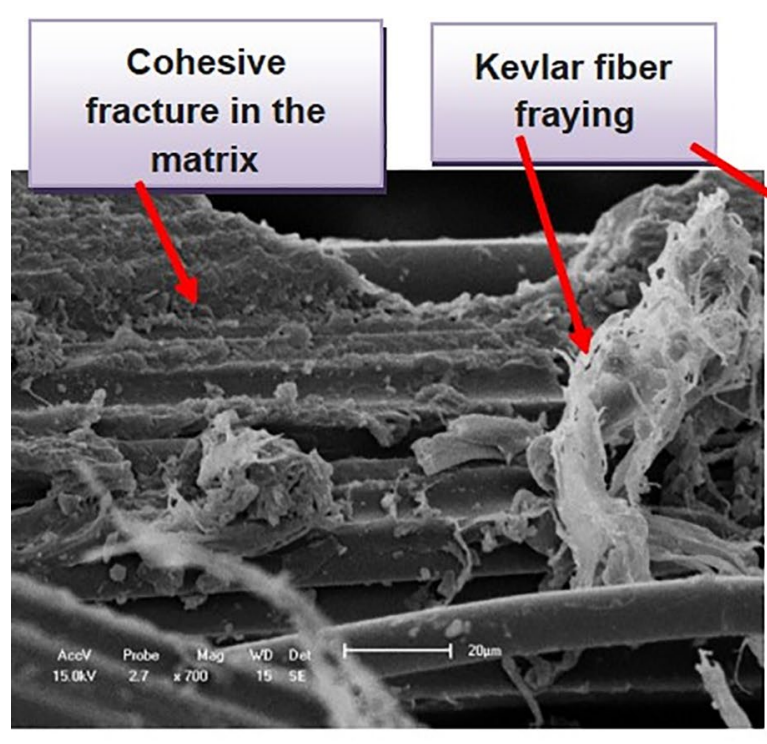

(a)

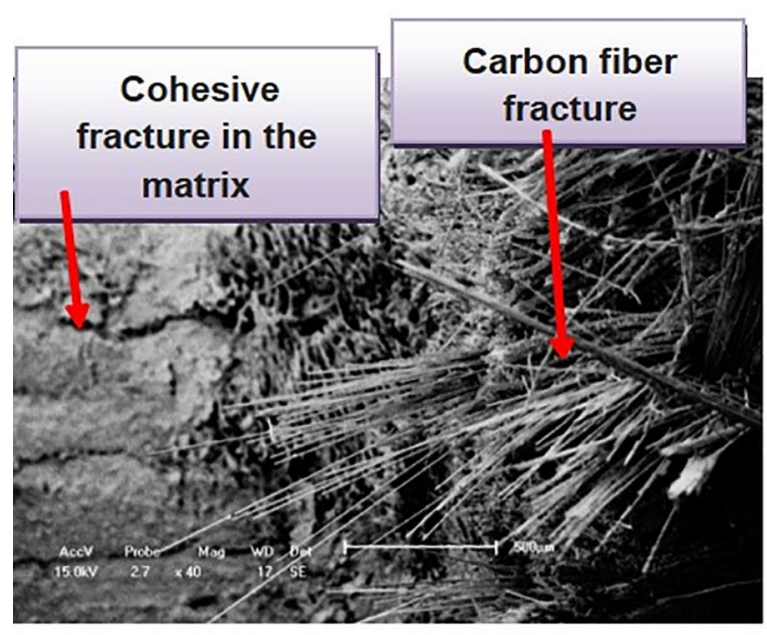

(c)

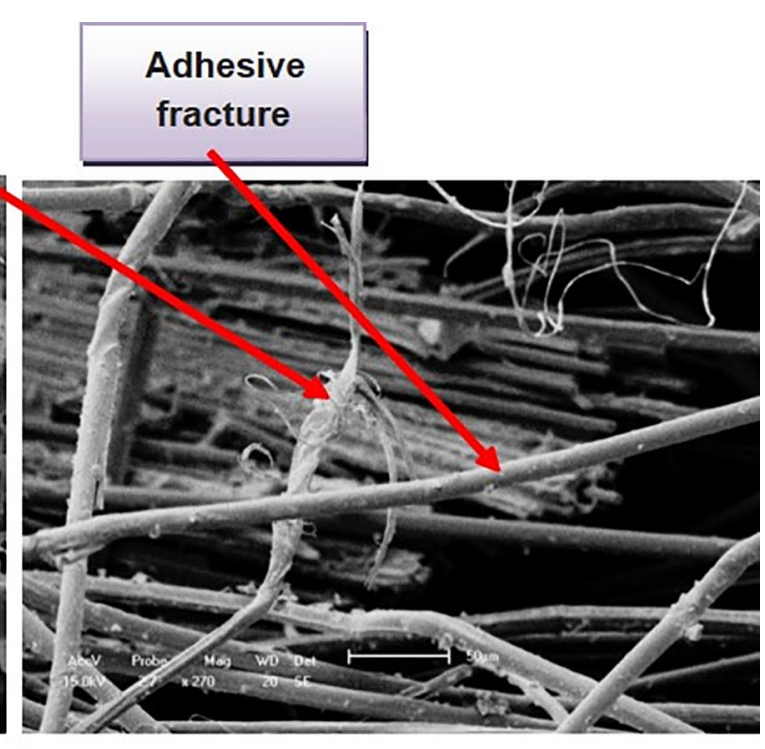

(b)

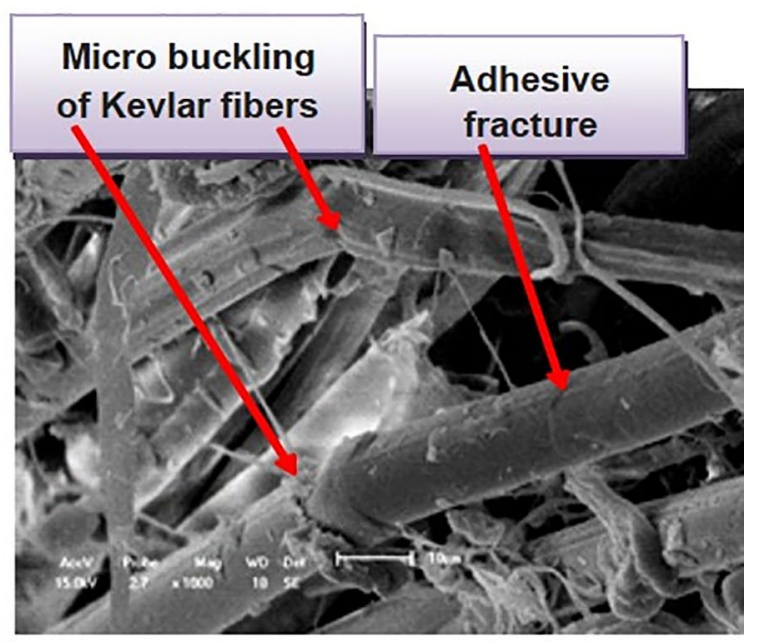

(d)

Figure 9. Mechanical fracture of the specimens: (a) CLCO; (b) CLKO; (c) CLCH and (d) CLKH.

\section{Conclusions}

- Neither anisotropy nor the presence of geometric discontinuity influenced the profile between stress and strain of the composite laminate, since linearly elastic behavior until fracture was observed in all the test specimens;

- Concerning to mechanical properties in the presence of anisotropy, losses of $7.23 \%$ and $31.78 \%$ in tensile strength and elastic modulus, respectively, were observed in CLKO test specimens when compared to CLCO specimens;
- The presence of a central hole had a direct influence on the response of the hybrid $\mathbf{C L}$. In the case of the load applied in the direction of the carbon fibers, greater losses in strength $(31.40 \%)$ than in rigidity $(3.71 \%)$ were observed in relation to the test specimens with holes; likewise, in the case of the load applied in the direction of the Kevlar fibers, greater losses in strength $(43.48 \%)$ than in rigidity $(9.31 \%)$ were registered for the test specimens with a hole; 
- The influence of anisotropy between the test specimens with the presence of a central hole promote greater losses in tensile strength $(23.56 \%)$ and elastic modulus (35.75\%) when comparing CLKH and CLCH test specimens;

- The study of the simultaneous influence of anisotropy and geometric discontinuity, in the case of test specimens CLCO and CLKH, resulted in greater losses in the properties of CLKH. This was considered the most critical situation, since losses in tensile strength and elastic modulus were $47.56 \%$ and $38.14 \%$, respectively;

- In the prediction of residual strength, the results showed that the PSC criterion was more accurate irrespective of the anisotropy present in the hybrid fabric;

- Micrographic analysis of the final damage showed characteristics such as fiber fracture, adhesive fracture (fiber/matrix debonding), Kevlar fiber fraying, in addition to the cohesive fracture in the matrix, for all the test specimens analyzed. The specimens tested in the direction of the Kevlar fibers showed more intense cracking in the matrix when compared to those tested in the direction of the carbon fibers.

\section{Acknowledgements}

The authors acknowledge Postgraduate Program in Mechanical Engineering by the access of their laboratories and $\mathrm{CNPq}$ for scholarships.

\section{References}

1. Jawaid M,Abdul Khalil HPS. Cellulosic/synthetic fibre reinforced polymer hybrid composites: A review. Carbohydrate Polymers. 2011;86(1):1-18.

2. Herakovich CT. Mechanics of Fibrous Composites. 1st ed. New York: Wiley; 1997. 480 p.

3. Batista ACMC, Oliveira JFS, Aquino EMF. Structural degradation and mechanical fracture of hybrid fabric reinforced composites. Polymer Engineering Science. 2016;56(6):657-668.

4. Batista ACMC, Tinô SRL, Fontes RS, Nóbrega SHS, Aquino EMF. Anisotropy and holes in epoxy composite reinforced by carbon/glass and carbon/aramid hybrid fabrics: Experimental and analytical results. Composites Part B: Engineering. 2017;125:9-18.

5. Alsaadi M, Erklig A, Alrawi H. Effect of S-glass fabric on the mechanical characteristics of a hybrid carbon/aramid fabric reinforced epoxy composites. Materials Research Express. 2017;4(5):055304.

6. Bejan L, Taranu N, Sîrbu A. Effect of Hybridization on Stiffness Properties of Woven Textile Composites. Applied Composite Materials. 2013;20(2):185-194.
7. Fontes RS, Bezerra HAD, Batista ACMC, Tinô SRL, Aquino EMF. Failure Theories and Notch Type Effects on the Mechanical Properties of Jute-Glass Hybrid Composite Laminates. Material Research. 2019;22(2):e20180269.

8. Tinô SRL, Fontes RS, de Aquino EMF. Theories of failure average stress criterion and point stress criterion in notched fiber-reinforced plastic. Journal of Composite Materials. 2014;48(21):2669-2676.

9. Liu CJ, Nijhof AHJ, Ernst LJ, Marissen R. A New Ultimate Strength Model of Notched Composite Laminates - Including the Effects of Matrix Failure. Journal of Composite Materials. 2010;44(11):1335-1349.

10. Srivastava VK, Kumar D. Prediction of Notched Strength of Laminated Fibre Composites under Tensile Loading Conditions. Journal of Composite Materials. 2002;36(9):1121-1133.

11. Toubal L, Karama M, Lorrain B. Stress concentration in a circular hole in composite plate. Composite Structures. 2005;68(1):3136.

12. Feraboli P, Peitso E, Cleveland T, Stickler PB, Halpin JC. Notched behavior of prepreg-based discontinuous carbon fiber/epoxy systems. Composites Part A: Applied Science and Manufacturing. 2009;40(3):289-299.

13. Tinô SRL, Aquino EMF. Notched GFRP: anisotropy, residual strength, and fracture characteristics. Journal of Reinforced Plastics and Composites. 2012;31(1):29-40.

14. Shin CS, Wang CM. An Improved Cohesive Zone Model for Residual Notched Strength Prediction of Composite Laminates with Different Orthotropic Lay-Ups. Journal of Composite Materials. 2004;38(9):713-736.

15. Hallett SR, Green BG, Jiang WG, Wisnom MR. An experimental and numerical investigation into the damage mechanisms in notched composites. Composites Part A: Applied Science and Manufacturing. 2009;40(5):613-624.

16. Mollenhauer D, Iarve EV, Kim R, Langley B. Examination of ply cracking in composite laminates with open holes: A moiré interferometric and numerical study. Composites Part A: Applied Science and Manufacturing. 2006;37(2):282-294.

17. Tan SC. Stress Concentrations in Laminated Composites. Lancaster/Basel: Technomic; 1994. 482 p.

18. ASTM International. ASTM D5766 / D5766M-11 - Standard Test Method for Open-Hole Tensile Strength of Polymer Matrix Composite Laminates. West Conshohocken: ASTM International; 2011.

19. Awerbuch J, Madhukar MS. Notched Strength of Composite Laminates: Predictions and Experiments -- A Review. Journal of Reinforced Plastics and Composites. 1985;4(1):3-159.

20. ASTM International. ASTM D3039 / D3039 M-14 Standard Test Method for Tensile Properties of Polymer Matrix Composite Materials. West Conshohocken: ASTM International; 2014.

21. ASTM International. ASTM D792-13 - Standard Test Methods for Density and Specific Gravity (Relative Density) of Plastics by Displacement. West Conshohocken: ASTM International; 2013. 
22. ASTM International. ASTM D3171-15 - Standard Test Methods for Constituent Content of Composite Materials. West Conshohocken: ASTM International; 2015.

23. Felipe RCTS, Felipe RNB, Batista ACMC, Aquino EMF. Polymer Composites Reinforced with Hybrid Fiber Fabrics. Materials Research. 2017;20(2):555-567.

24. Felipe RNB, Felipe RCTS, Aquino EMF. Laminar composite structures: Study of environmental aging effects on structural integrity. Journal of Reinforced Plastics and Composites. 2012;31(21):1455-1466.
25. Hull D, Clyne TW. An Introduction to Composite Materials. 2nd ed. Cambridge: Cambridge University; 1996. 326 p.

26. Oliveira JFS, Leão MA, Batista ACMC, Tinô SRL, Aquino EMF. Study on Mechanical Properties and Fracture in Epoxy Composites Reinforced by Hybrid Twill Fabrics. Fibers Polymers. 2018;19(5):1109-1118.

27. Budynas RG, Nisbett JK. Shigley's Mechanical Engineering Design. 8th ed. New York: McGraw-Hill; 2008. 1059 p. 